\title{
Loss of Heterozygosity and Promoter Methylation, but not Mutation, May Underlie Loss of TFF1 in Gastric Carcinoma
}

\author{
Ralph Carvalho, Tuncay Kayademir, Paula Soares, Paulo Canedo, Sónia Sousa, \\ Carla Oliveira, Peter Leistenschneider, Raquel Seruca, Peter Gött, Nikolaus Blin, \\ Fátima Carneiro, and José Carlos Machado
}

Institute of Molecular Pathology and Immunology of the University of Porto (IPATIMUP) (RC, PS, PC, SS, CO, RS, FC, JCM), Faculty of Medicine (PS, PC, RS, FC, JCM), and Hospital de S. João (FC), Porto, Portugal; and Division of Molecular Genetics (TK, PL, PG, NB), Institute of Anthropology and Human Genetics, University of Tübingen, Tübingen, Germany

\begin{abstract}
SUMMARY: It has been advanced that the trefoil factor (TFF) 1 gene is a candidate tumor-suppressor gene and may be involved in the development and/or progression of human gastric cancer. We aimed to clarify the putative role of TFF1 in gastric carcinogenesis. Ninety gastric carcinomas and eight gastric carcinoma-derived cell lines were screened for TFF1 mutations; subsets of the primary tumors and of the cell lines were subjected to loss of heterozygosity (LOH), immunohistochemistry, and promoter methylation analyses. TFF1 mutations were not detected in any of 90 gastric carcinomas. Eight (28\%) of 28 informative cases displayed LOH at the TFF1 locus and absence of TFF1 staining by immunohistochemistry. These results indicate a frequent loss of TFF1 expression in gastric carcinomas through a mutation-independent mechanism. Extensive TFF1 promoter methylation was observed in nonexpressing gastric carcinoma-derived cell lines and tissues. Expressing cell lines, as well as normal gastric mucosa, presented little or no methylation of the promoter. Gastric carcinoma DNA presented de novo methylation of the promoter. These results point to the involvement of promoter methylation in the shutting down of TFF1. We conclude that TFF1 point mutations seem to be a rare event in gastric carcinogenesis. The loss of expression of TFF1 in a proportion of gastric carcinomas may be explained by LOH and methylation of the TFF1 promoter region. Our results further support the role of TFF1 inactivation in gastric carcinogenesis, in agreement with the results obtained in the Tff1-knockout mice model. (Lab Invest 2002, 82:1319-1326).
\end{abstract}

$T$ FF1 (originally pS2) is a member of the trefoil factor (TFF) domain peptides. Trefoil peptides are small and stable molecules characterized by a three-loop structure formed by three cysteine disulfide bonds (Thim, 1989). TFFs are ectopically induced in cells of regenerating tissues surrounding areas of damage during wound healing in ulcerative and inflammatory bowel diseases (Wong et al, 1999; Wright et al, 1993). The possibility of trefoil peptides being involved in the repair and maintenance of mucosal integrity has therefore been raised.

The expression of TFF1 is lower in gastric intestinal metaplasia and gastric adenomas than in the adjacent normal gastric mucosa, and its expression is completely lost in $40 \%$ to $60 \%$ of gastric carcinomas (Machado et

DOI: 10.1097/01.LAB.0000029205.76632.A8

Received April 9, 2002.

This work was supported by CRUP/DAAD (314-Al-p-dr; Acção Integrada Luso-Alemãa A-10/00); by Fundação para a Ciência e Tecnologia (POCTII 1999/MGI/35586); and by Programa Operacional Ciência, Tecnologia e Inovação, do Quadro Comunitário de Apoio III.

Address reprint requests to: Dr. José Carlos Machado, IPATIMUP, Rua Roberto Frias, s/n, 4200-465 Porto, Portugal.E-mail: josem@ipatimup.pt al, 1996a, 1996b). Lefebvre et al (1996) produced a mouse strain deficient in Tff1 by homologous recombination, resulting in decreased and dysfunctional gastric mucin production by the Tff1-knockout mice. These mice also displayed marked antral hyperplasia and dysplasia. At five months, all mice had developed antral adenomas; $30 \%$ of these mice further developed multifocal intramucosal carcinomas (Lefebvre et al, 1996). Moreover, it has been shown that region 21q22, where the TFF1 gene is located, is commonly deleted in gastric carcinoma (Sakata et al, 1997), and that TFF1 promoter methylation is associated with reduced TFF1 expression in intestinal metaplasia and gastric carcinoma (Fujimoto et al, 2000). Notably, it has been demonstrated that expression of TFF1 is controlled by methylation in the promoter region in human breast cancer cell lines (Martin et al, 1997). Taken together, the aforementioned findings suggest that TFF1 might be considered a tumorsuppressor gene and may be involved in the development and/or progression of human gastric cancer.

The importance of TFF1 in gastric carcinogenesis has been emphasized recently by Park et al (2000), who reported eight missense mutations of the TFF1 gene in one gastric adenoma and seven gastric carcinomas. All mutations were confined to loops I and II 
of the TFF1 three-loop structure and could, according to Park et al (2000), affect the protein structure and impair its function. Loss of heterozygosity ( $(\mathrm{OH})$ was also reported in one gastric adenoma and four gastric carcinomas (Park et al, 2000).

In the present study, we aimed to clarify the putative role of TFF1 in gastric carcinogenesis. Initially we attempted to confirm the findings of Park et al (2000) by screening a series of 90 Portuguese patients with gastric carcinoma for TFF1 somatic mutations. The results we obtained, however, do not support the role for TFF1 mutations in gastric carcinogenesis. We subsequently analyzed a subset of cases for TFF1 LOH, TFF1 immunohistochemical expression, and TFF1 promoter methylation status. Although mutations seem to be absent, LOH and loss of immunoexpression were found to occur frequently in gastric carcinoma. TFF1 promoter methylation was demonstrated to be associated with loss of TFF1 expression, and might therefore constitute an alternative mechanism for TFF1 shutdown in gastric carcinogenesis.

\section{Results}

\section{Mutation Detection}

Screening of the three exons of the TFF1 gene (including intron/exon boundaries) in a series of 90 gastric carcinoma cases and eight gastric carcinoma cell lines revealed six different single strand conformation polymorphism (SSCP) variants (Fig. 1). Sequencing of these variants resulted in the identification of five noncoding nucleotide substitutions and one missense substitution (Table 1). All six sequence variants were found in normal DNA counterparts. The $-2 \mathrm{C} \rightarrow \mathrm{T}$, $73 G \rightarrow A$, and $85+8 G \rightarrow A$ variants were also found in a control group of 98 blood donors. There was no statistical difference between the gastric carcinoma and control group sequence variant frequencies (data not shown). The $3^{\prime}$ untranslated region variants were not screened in the control group. RT-PCR/SSCP screening of $31 \mathrm{cDNAs}$ did not reveal any additional sequence alterations and confirmed the $-2 \mathrm{C} \rightarrow \mathrm{T}$ and $73 \mathrm{G} \rightarrow$ A nucleotide substitutions found in corresponding gastric carcinoma DNAs.

\section{LOH Analysis}

Thirty-five randomly selected gastric carcinoma cases from the original series were tested for $\mathrm{LOH}$, of which 28 were found to be informative for at least one of the chosen markers. We observed LOH in $10(36 \%)$ cases (Fig. 2). The penta-nucleotide repeat TTTTC-marker was lost in eight cases. Within these eight cases, $\mathrm{LOH}$ also involved other loci. A detailed map of the markers displaying $\mathrm{LOH}$ is depicted in Table 2. In two cases, $\mathrm{LOH}$ was seen only for the D21S1225 marker; both cases showed retention in markers proximal to TFF1 and were therefore not considered $\mathrm{LOH}$-positive for the TFF1 locus. No association was found between the tumor histologic type and the presence of $\mathrm{LOH}$ (Table 2).

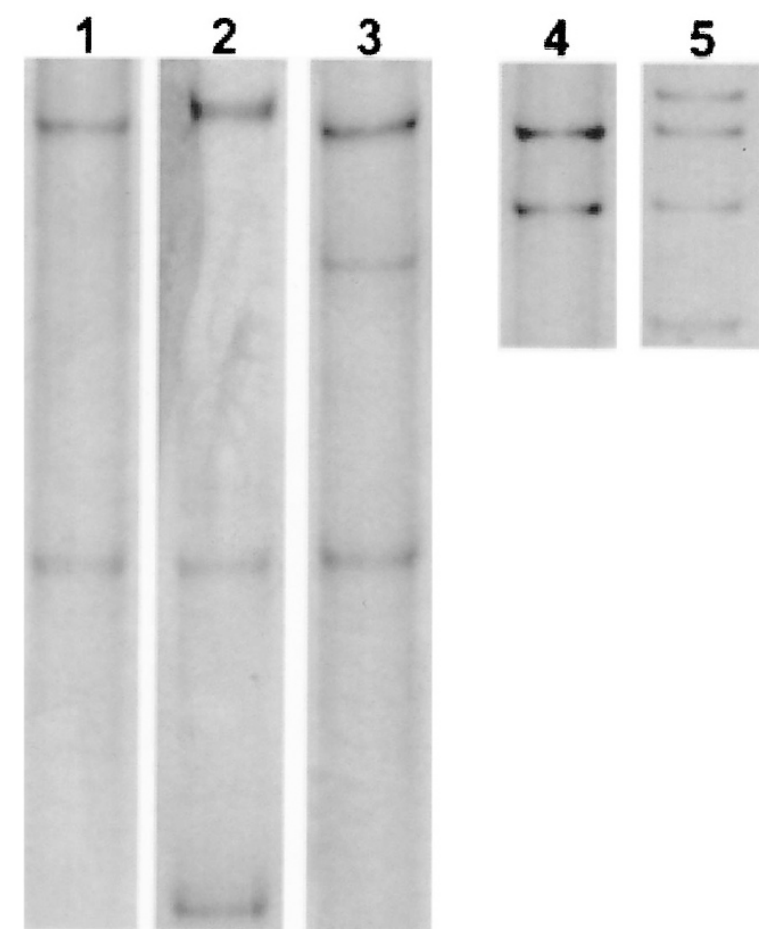

Figure 1.

PCR/single strand conformation polymorphism analysis of the TFF1 gene in gastric carcinomas. Lane 1, exon 1 normal band pattern (Case 32A). Lane 2, exon 1 missense substitution $(73 \mathrm{G} \rightarrow \mathrm{A})$ (Case $33 \mathrm{~A})$. Lane 3 , exon 1, $5^{\prime}$ untranslated region nucleotide substitution $(-2 \mathrm{C} \rightarrow \mathrm{T})$ (Case 31A). Lane 4, exon 3 normal band pattern (Case $71 \mathrm{~A})$. Lane 5, 3' untranslated region nucleotide substitution $(255+41 \mathrm{G} \rightarrow \mathrm{A})$ (Case $69 \mathrm{~A})$.

Table 1. Summary of the Results of TFF1 PCR/SSCP Screening in a Series of $\mathbf{9 0}$ Gastric Carcinoma Cases

\begin{tabular}{lccc}
\hline Location & $\begin{array}{c}\text { Nucleotide } \\
\text { change }^{a}\end{array}$ & $\begin{array}{c}\text { Predicted protein } \\
\text { change }\end{array}$ & Frequency (\%) \\
\hline 5' UTR & $-2 \mathrm{C} \rightarrow \mathrm{T}$ & - & $35 / 90(38.9)$ \\
Exon 1 & $73 \mathrm{G} \rightarrow \mathrm{A}$ & E25K (missense) & $4 / 90(4.4)$ \\
Intron 1 & $85+8 \mathrm{G} \rightarrow \mathrm{A}$ & - & $49 / 90(54.4)$ \\
3' UTR & $255+29 \mathrm{C} \rightarrow \mathrm{C}$ & - & $1 / 90(1.1)$ \\
3' UTR & $255+33 \mathrm{G} \rightarrow \mathrm{A}$ & - & $1 / 90(1.1)$ \\
3' UTR & $255+41 \mathrm{G} \rightarrow \mathrm{A}$ & - & $6 / 90(6.7)$ \\
\hline
\end{tabular}

${ }^{a}$ Numbering is according to the CDNA starting at $\mathrm{A}$ in start codon (GenBank Accession No. AB038162).

\section{Immunohistochemical Analysis}

In the eight cases positive for LOH, TFF1 expression was evaluated by immunohistochemistry (IHC). No presence of the TFF1 protein was observed in tumor cells, whereas in normal gastric mucosa controls, TFF1 was synthesized throughout the superficial and foveolar epithelium (Fig. 3).

\section{Promoter Methylation Analysis}

Methylation analysis was performed in the -115 to +143 region of the TFF1 promoter encompassing 10 $\mathrm{CpG}$ sites (a region previously shown to be involved in the control of TFF1 expression by methylation in breast 

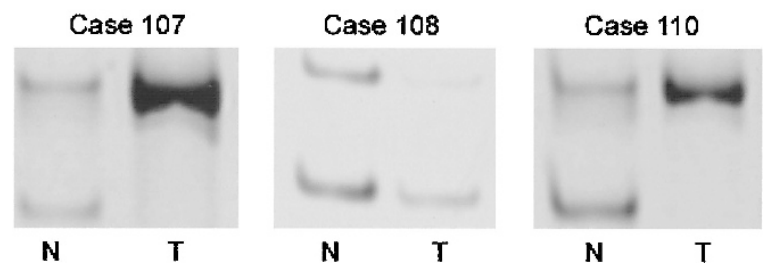

Figure 2.

Loss of heterozygosity at the penta-nucleotide repeat TTTTC-marker in cases 107, 108, and 110. N, normal DNA; T, tumor DNA.

cancer-derived cell lines). Sequencing of individual clones of bisulfite-treated DNA (20 clones analyzed) showed the TFF1-expressing gastric carcinoma-derived cell line GP220 to bear a predominantly negative promoter methylation pattern (Fig. 4a). By contrast, the TFF1-negative gastric carcinoma-derived GP202 cell line was found to be extensively methylated in the promoter region (Fig. 4b).

GP202 cells were subsequently subjected to treatment with 5-aza-2' deoxycytidine (5-aza-CdR), a demethylating agent, which led to renewed TFF1 expression by GP202. Further, RT-PCR analysis showed the increase in 5-aza-CdR administered to the cells to correspond to an increased TFF1 expression by GP202 (Fig. 5). This effect was better disclosed by quantitative real-time PCR, which showed a significant and strong increase of TFF1 mRNA in GP202 cells (Fig. 6). Normalized to the mRNA expression of housekeeping gene encoding for human glyceraldehyde-3-phosphate dehydrogenase (GAPDH) and a null-control, a concentration of $0.01 \mu \mathrm{M} 5$-aza-CdR resulted in a 16-fold increase of TFF1 expression, a 55-fold up-regulation was observed using $1 \mu \mathrm{M}$ 5-aza$\mathrm{CdR}$, and $10 \mu \mathrm{M}$ 5-aza-CdR was responsible for a 113-fold increase of TFF1 expression.

The methylation pattern was determined in three gastric carcinoma cases (intestinal-type, negative for TFF1 expression), in which tumoral DNAs and corresponding normal gastric mucosas were subjected to bisulfite treatment and analyzed (average of 30 clones per sample). An average methylation of $25 \%$ to $50 \%$ was found in 9 of the $10 \mathrm{CpG}$ sites analyzed (the exception being position +70 ) of the TFF1 5 ' flanking region in normal gastric mucosa (Fig. 7, a and C). On the other hand, the results show an increased ( $>75 \%$ ) methylation of the TFF1 $5^{\prime}$ flanking region in the tumoral DNAs (Fig. 7, b and d). Little heterogeneity was found in the methylation pattern of individual clones.

\section{Discussion}

An increasing body of evidence links TFF1, a protein expressed in the surface/foveolar epithelium of the stomach, to gastric carcinogenesis. The apparent importance of TFF1 in gastric carcinogenesis was once again rekindled when recently Park et al (2000) reported somatic mutations of the TFF1 gene in gastric carcinomas. These mutations were detected in 1 of 18 gastric adenomas and in 7 of 43 gastric carcinomas and were confined to five codons.
We performed an analysis encompassing all three TFF1 exons and respective exon/intron boundaries on 90 gastric carcinomas. The screening revealed six alterations, four of which, including the $73 \mathrm{G} \rightarrow \mathrm{A}$ missense substitution, were present in at least $4.4 \%$ of the cases (Table 1). Furthermore, all six sequence variants were found in normal DNA counterparts, and the $-2 \mathrm{C} \rightarrow \mathrm{T}, 73 \mathrm{G} \rightarrow \mathrm{A}$, and $85+8 \mathrm{G} \rightarrow \mathrm{A}$ variants were also found in a control group of 98 blood donors. Together these results suggest a polymorphic nature for the above-described DNA sequence alterations and do not, therefore, support the role of mutations in the inactivation of TFF1 reported by Park et al (2000).

The reasons for the apparent discrepancy between our results and those of Park et al (2000) are not clear. Looking back at the results obtained by Park et al (2000), we see that three alterations, two of which were identical, were detected in codon 8 , and two identical alterations were seen in codon 13. Furthermore, a study of the evolutionary origin of the TFFdomain (Sommer et al, 1999) suggests that these codons are not highly conserved across species. The same holds true for codons 10 and 22, where mutations were also reported by Park et al (2000). Moreover, no information was provided regarding the somatic or germline nature of these alterations. The pathogenic role of these alterations remains therefore to be clarified, and there is a suggestion that at least some of the alterations described by Park et al (2000) may be polymorphic in nature. Moreover, the role played by the different populational/geographical backgrounds of the two studies cannot be excluded.

Because the role of mutations in the shutdown of TFF1 remains unclear, and because $\mathrm{LOH}$ has been described as a mechanism responsible for the loss of expression of TFF1 (Sakata et al, 1997), a random group of gastric carcinomas was selected for an $\mathrm{LOH}$ study. In 28 informative cases, eight showed LOH for a penta-nucleotide repeat marker flanking the TFF1 gene. In addition, two cases displayed LOH solely for the D21S1225 marker while showing retention in markers more proximal to TFF1, and were thus not considered to harbor LOH for the TFF1 locus. Deletion mapping analysis of the $\mathrm{LOH}$ cases allowed us to confine the deleted region to the TFF1 gene. The eight $\mathrm{LOH}$ cases were then selected for an IHC analysis of TFF1. Interestingly, none of the eight LOH-positive cases presented TFF1 expression in the tumor region. It has also been previously shown that TFF1 expression is lost in $40 \%$ to $60 \%$ of gastric carcinomas (Machado et al, 1996a). Altogether these results indicate that TFF1 is frequently lost in gastric carcinogenesis in a mutation-independent mechanism.

The involvement of promoter methylation in the regulation of TFF1 expression had been previously suggested (Martin et al, 1995). An attempt was thus made to link this epigenetic event to loss of expression of TFF1 in gastric carcinomas. To achieve our goal, it proved necessary to delineate an area within the promoter region of TFF1 that encompassed CpG sites that might prove influential for the methylation of the promoter. In doing so, we partly used a CpG-rich area 
Table 2. Result of Analyses of Polymorphic Markers in Informative Gastric Carcinomas Positive for Loss of Heterozygosity

\begin{tabular}{|c|c|c|c|c|c|c|}
\hline \multirow[b]{2}{*}{ Case } & \multirow{2}{*}{$\begin{array}{l}\text { Histologic } \\
\text { type }^{a}\end{array}$} & \multicolumn{5}{|c|}{ Marker $^{b}$} \\
\hline & & TAAAA & 169B4.GT118 & TTTTC & TTTC & D21S1225 \\
\hline 99 & 1 & HET/RER & $\mathrm{NI}$ & $\mathrm{LOH}$ & $\mathrm{NI}$ & HET \\
\hline 107 & A & $\mathrm{NI}$ & $\mathrm{NI}$ & $\mathrm{LOH}$ & $\mathrm{NI}$ & $\mathrm{LOH}$ \\
\hline 108 & D & $\mathrm{NI}$ & HET/RER & $\mathrm{LOH}$ & $\mathrm{NI}$ & HET \\
\hline 110 & A & $\mathrm{LOH}$ & $\mathrm{NI}$ & $\mathrm{LOH}$ & $\mathrm{NI}$ & $\mathrm{LOH}$ \\
\hline 113 & I & RER & $\mathrm{NI}$ & $\mathrm{LOH}$ & RER & $\mathrm{NI}$ \\
\hline 121 & D & $\mathrm{LOH}$ & $\mathrm{NI}$ & $\mathrm{LOH}$ & HET & HET \\
\hline 157 & I & $\mathrm{NI}$ & $\mathrm{NI}$ & $\mathrm{LOH}$ & $\mathrm{LOH}$ & $\mathrm{NI}$ \\
\hline 209 & A & HET & HET & $\mathrm{LOH}$ & HET & $\mathrm{NI}$ \\
\hline 132 & 1 & HET & HET & $\mathrm{NI}$ & HET & $\mathrm{LOH}$ \\
\hline 141 & D & HET & HET & $\mathrm{NI}$ & HET & $\mathrm{LOH}$ \\
\hline
\end{tabular}

${ }^{a} \mathrm{~A}$, atypical; $\mathrm{D}$, diffuse-type; I, intestinal-type.

${ }^{b} \mathrm{HET}$, retaining heterozygosity; LOH, loss of heterozygosity; NI, noninformative; RER, replication error.

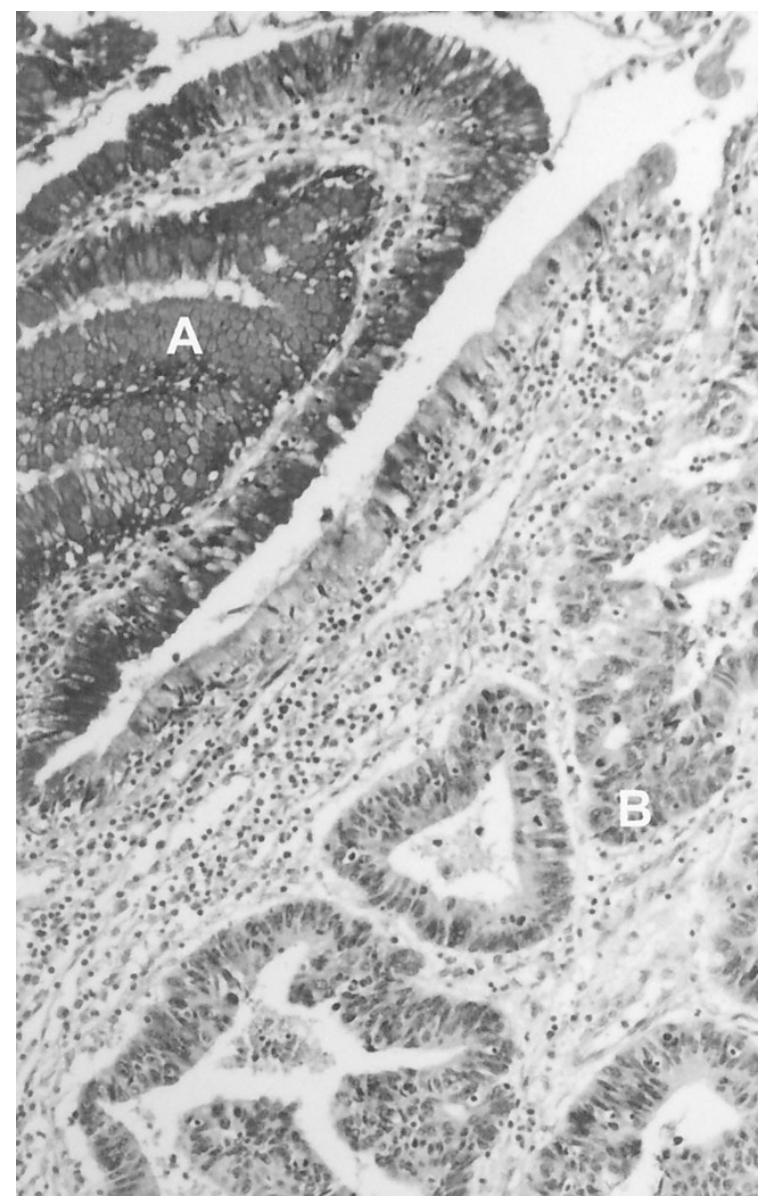

Figure 3.

Immunohistochemistry of section encompassing trefoil factor (TFF) 1-positive normal mucosa $(A)$ and TFF1-negative intestinal-type gastric carcinoma $(B)$ from Case $99 \mathrm{~A}$.

chosen by Martin et al $(1995,1997)$ in their studies, expanding the region downstream to cover a further three CpG sites. The TFF1 5 ' flanking region decided on contains $10 \mathrm{CpG}$ sites (positions $-84,-56,-20$, $-13,-9,+11,+17,+70,+100$, and +112 in relation to the transcription start site) flanking the TATA box

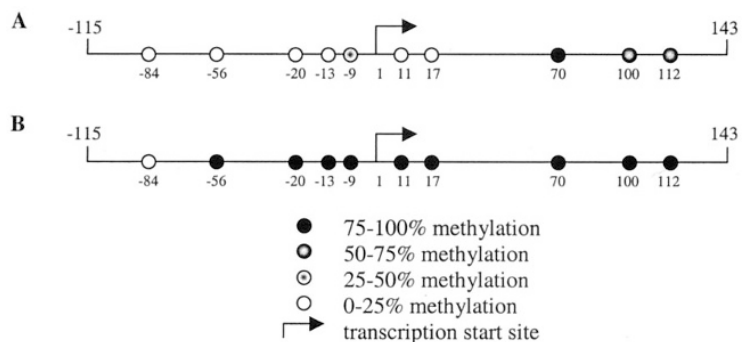

Figure 4.

Methylation pattern in the -115 to +143 region of the TFF1 promoter. A, TFF1-expressing GP220 cell line with a predominantly negative promoter methylation pattern. B, TFF1 nonexpressing GP202 cell line with a predominant positive methylation pattern.

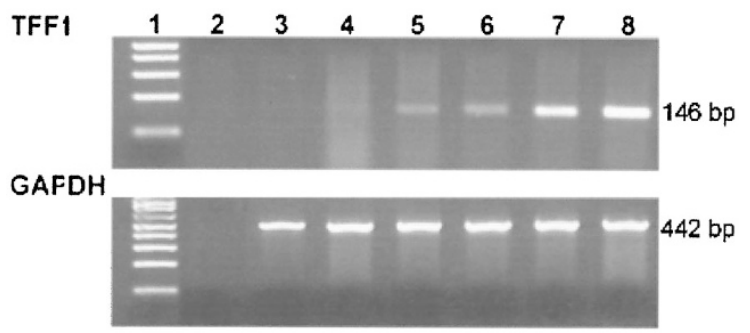

Figure 5.

GP202 TFF1 expression after 5-aza-CdR treatment. Lane 1, 100 bp DNA size marker. Lane 2, negative control. Lane 3, blood sample. Lane 4, GP202 $0 \mu \mathrm{m}$ 5-aza-CdR. Lane 5, GP202 $1 \mu \mathrm{m}$ 5-aza-CdR. Lane 6, GP202 $5 \mu \mathrm{m}$ 5-aza-CdR. Lane 7, GP202 $10 \mu \mathrm{M}$ 5-aza-CdR. Lane 8, GP220 positive control.

(position -29) and the start codon (position +40). Additionally, it includes in its sequence two Hpall restriction sites (CCGG) (positions -85 and -21 ) previously shown by Fujimoto et al (2000) to be targets in TFF1 promoter methylation. Further, CpG site -20 is four nucleotides downstream of the TATA box; CpG site -56 is seven nucleotides upstream of motif 4 , the binding site of hepatocyte nuclear factor $3 \beta$, previously shown to activate TFF1 expression (Beck et al, 1999), and three nucleotides downstream of the GATA-6 binding site, known to be TFF1-activating (Al azzeh et al, 2000). 


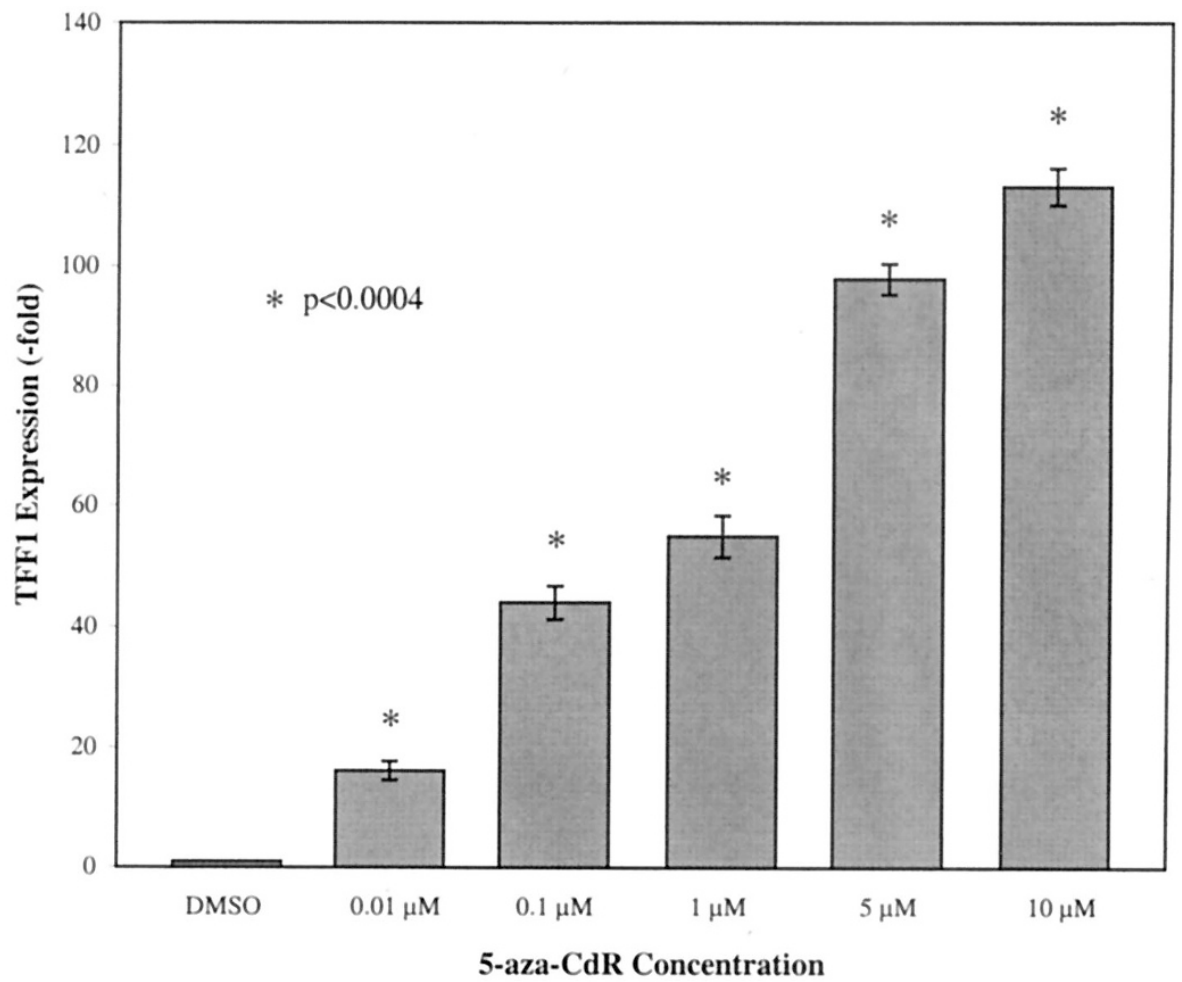

Figure 6.

GP202 TFF1 expression after 5-aza-CdR treatment by quantitative real-time PCR. Independent triplicate stimulation experiments were performed and analyzed by Student's $t$ test, $p<0.0004$. Error bars represent \pm one standard deviation.

As expected from the TFF1-expressing nature of the gastric carcinoma-derived cell line GP220, a predominantly negative promoter methylation pattern was established. This result is in contrast to the extensively methylated 5 ' flanking region of TFF1 in the TFF1negative gastric carcinoma-derived GP202 cell line. To link promoter methylation directly with expression of TFF1, we subjected GP202 cells to treatment with 5-aza-CdR, a demethylating agent. As predicted, demethylation of the promoter led to renewed TFF1 expression by the GP202 cells, demonstrated both by RT-PCR and quantitative real-time PCR. The results obtained are indicative of a correlation between methylation of the promoter in cells that are not TFF1expressing, and the absence of promoter methylation in cells that do express TFF1.

Our results indicate moreover that no single $\mathrm{CpG}$ site can be considered fundamental regarding the methylation status of the promoter region. Some $\mathrm{CpG}$ pairs are found to be methylated (eg, CpG site at position +70) regardless of the "assigned" methylation pattern and corresponding TFF1 expression. Further evidence can be observed in cell line GP202, where position -84 is unmethylated despite the methylated status of the TFF1 promoter region. The methylation of the promoter (or lack thereof) seems therefore to be a regional event, perhaps targeted at certain $\mathrm{CpG}$ areas, but not restricted to individual $\mathrm{CpG}$ sites.

In normal gastric mucosa, where TFF1 is consistently expressed throughout the superficial and foveolar epithelium, the observed methylation of $25 \%$ to
$50 \%$ at all $\mathrm{CpG}$ sites but one (position +70 ) of the TFF1 promoter probably reflects the heterogeneous cellular composition of gastric mucosa samples wherefrom DNA was obtained. In other words, methylated sequences found in normal gastric mucosa were probably derived from "contaminating" nonepithelial cells (eg, fibroblasts and inflammatory cells). This was confirmed by our results showing that blood and thyroid cells (both demonstrated not to express TFF1; Rio et al, 1988) present a positive methylation pattern, suggesting that TFF1 promoter methylation is the normal shutdown mechanism in nonexpressing tissues. Moreover, we found little heterogeneity in the methylation pattern of individual clones; the majority of the sequences are either methylated at all CpG sites or at none except for one CpG site (position +70) of the TFF1 5 ' flanking region.

The tumoral tissues presented a definite methylation of the promoter region, with an average methylation of $75 \%$ to $100 \%$ at the majority of CpG sites analyzed in the TFF1 5' flanking region, indicating that a de novo hypermethylation of the TFF1 promoter occurs as an event in the gastric carcinogenesis pathway.

In conclusion, TFF1 point mutations seem to be a rare event in gastric carcinogenesis. The loss of expression of TFF1 in a proportion of gastric carcinomas may be explained, however, by $\mathrm{LOH}$ and methylation of the TFF1 promoter region. Our results further support the role of TFF1 inactivation in gastric carcinogenesis, in agreement with the results obtained in Tff1-knockout mice. However, the precise nature of 
A

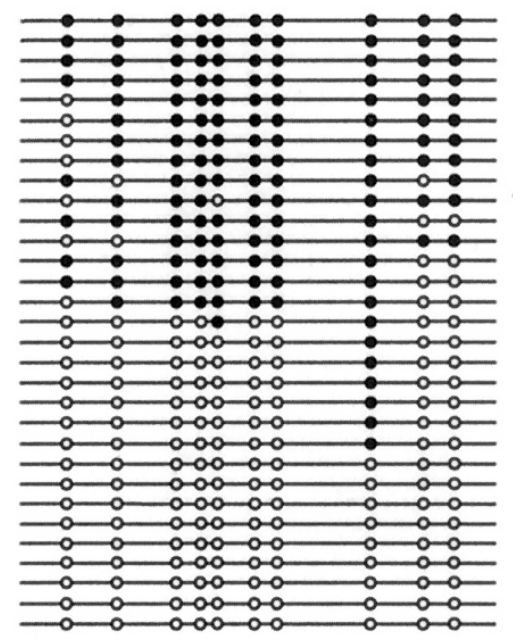

B

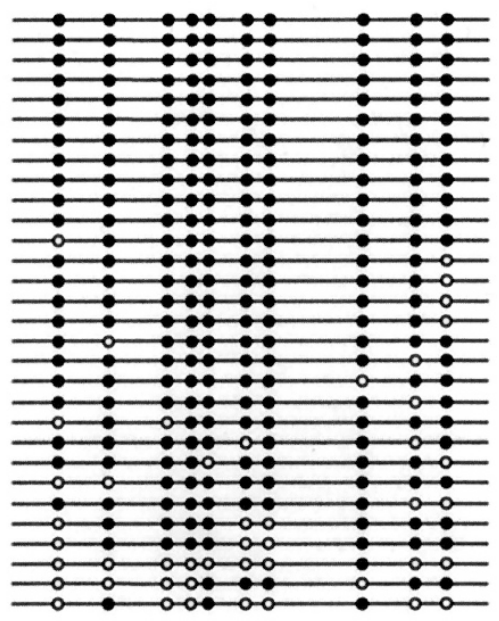

Methylated

$\bigcirc$ Unmethylated

C

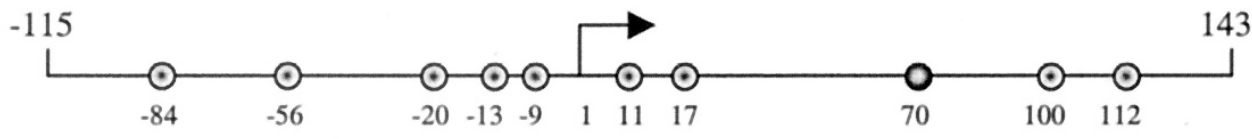

$\begin{array}{llllllllllll}-84 & -56 & -20 & -13 & -9 & 1 & 11 & 17 & 70 & 100 & 112\end{array}$

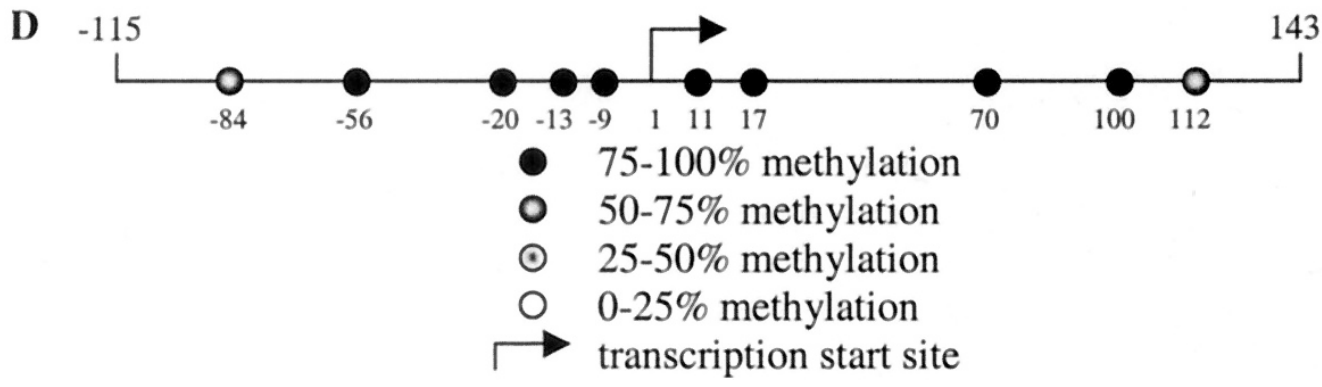

Figure 7.

TFF1 promoter methylation in DNA from the normal gastric mucosa and gastric carcinoma of the same individual. A, Methylation status at each analyzed CpG site in individual clones of the normal gastric mucosa from Case 151C. B. Methylation status at each analyzed $\mathrm{CpG}$ site in individual clones of the gastric carcinoma tissue of Case 151A. C, Average methylation at each analyzed CpG site of the TFF1 promoter in the normal gastric mucosa from Case 151C. D, Average methylation at each analyzed CpG site of the TFF1 promoter in the gastric carcinoma tissue from Case 151A.

TFF1 involvement in the gastric carcinoma pathway remains to be clarified.

\section{Materials and Methods}

\section{Materials}

Surgical specimens from 90 gastric carcinomas resected and diagnosed at Hospital S. João/Medical Faculty and IPATIMUP, Porto, Portugal, were studied. According to Laurén's classification, cases were classified as intestinal $(n=39)$, diffuse $(n=29)$, and atypical $(n=$ 22) carcinomas. Gastric carcinoma-derived cell lines GP220 (Gärtner et al, 1996), GP202 (Gärtner et al, 1996), MKN45 (Motoyama et al, 1986), KATO-III (Sekiguchi et al, 1978), L195 (Carvalho et al, 2001), St2957 (Vollmers et al, 1993), St3051 (Vollmers et al, 1993), and St23132
(Vollmers et al, 1993) were also studied. In addition, blood donors $(n=98)$ from the same geographic region as the patients with gastric carcinoma were used as controls. DNA from patients with gastric carcinoma was isolated from frozen samples of both neoplastic and non-neoplastic tissue. DNA from the control group was isolated from blood samples and collected after obtaining informed consent.

\section{Mutation Screening}

Genomic DNA was retrieved from the available material using standard phenol/chloroform extraction. Total RNA was extracted as previously described (Chomczynski and Sacchi, 1987). cDNA first-strand synthesis was made by random 6-mer priming using M-MLV 
reverse transcriptase at $37^{\circ} \mathrm{C}$ for 1 hour in the presence of $7 \mathrm{mM} \mathrm{MgCl}$.

TFF1 was screened by cold PCR/SSCP analysis, performed by PCR amplification of the complete TFF1 coding sequence with primers designed to amplify each TFF1 exon, including exon/intron boundaries. Primer sequences were as follows: exon 1 forward, 5 '-actcggggtcgcctttggagcag-3'; exon 1 reverse, 5'-ggccccacagagcaggaagaagca-3'; exon 2 forward, 5'-ttgcttcttacctgtgcactttca-3'; exon 2 reverse, 5'-ataccttctggagggacgtcg3'; exon 3 forward, 5'-ctcctcactaaagcatctctttct-3'; exon 3 reverse, 5'-cgagctctgggactaatcac-3'. Cold PCR amplifications were performed in a $25 \mu$ l volume containing $200 \mu \mathrm{m}$ of each dNTP, $20 \mathrm{pmol}$ of each of the forward and reverse sets of primers, $50 \mathrm{~mm} \mathrm{KCl}, 10 \mathrm{~mm}$ Tris- $\mathrm{HCl}$ ( $\mathrm{pH}$ 9.0), $1.5 \mathrm{~mm} \mathrm{MgCl}_{2}$, and $1 \mathrm{U}$ of TaqDNA polymerase (Amersham Biosciences, Piscataway, New Jersey). Cycling conditions were 30 seconds at $94^{\circ} \mathrm{C}, 30$ seconds at $60^{\circ} \mathrm{C}$, and 30 seconds at $72^{\circ} \mathrm{C}$ for 35 cycles for all three exons. RT-PCR amplification of the available cDNAs ( $n=31$ ) was performed using the following primers: forward, 5'-ggtcgcctttggagcagaga-3'; reverse, 5'caggatgcaggcagatccct- $3^{\prime}$. Cycling conditions were 30 seconds at $94^{\circ} \mathrm{C}, 30$ seconds at $58^{\circ} \mathrm{C}$, and 30 seconds at $72^{\circ} \mathrm{C}$ for 35 cycles. PCR negative controls were performed by replacing the template DNA with water.

For SSCP analysis, PCR reaction products were diluted 1:1 with loading buffer $(95 \%$ formamide, $0.05 \%$ bromophenol blue, and $0.05 \%$ xylene cyanol), denatured at $98^{\circ} \mathrm{C}$ for 10 minutes and cooled on ice for 5 minutes. Electrophoresis of the denatured PCR products was carried out in nondenaturing $0.8 \mathrm{X}$ mutation detection enhancement gels (BMA, Rockland, Maine) at $2 \mathrm{~W}$ and $20^{\circ} \mathrm{C}$ for 15 hours. PCR/SSCP products were visualized by standard DNA silver staining. The SSCP banding pattern was interpreted through the recovery of bands from the mutation detection enhancement gels and cold PCR reamplification of the DNA using the original sets of primers. Reamplification products were purified and sequenced using the $A B I$ Prism Dye Terminator Cycle Sequencing kit (PerkinElmer, Foster City, California) and an ABI Prism 377 DNA Sequencer (Perkin-Elmer). Sequencing was performed on both strands using the original primers.

\section{LOH Analysis}

The LOH study was performed on 35 randomly selected gastric carcinoma DNAs and on matched constitutional DNAs from the original series. Cold PCR amplification of the following microsatellite markers was performed according to the procedures described above for PCR: TAAAA-marker, repeat region 242741..242809, GenBank accession number AP001746; TITC-marker, repeat region 193259..193322, GenBank accession number AP001746; TTTC-marker, repeat region 167739..167779, GenBank accession number AP001746; 169B4.GT118 (Berry et al, 2000); and D21S1225 (Berry et al, 2000). Primer sequences were as follows: TAAAA-marker forward, 5'-tgggtgacagagaaagactcca-3'; TAAAA-marker reverse, 5'-ggtagctgctgcgtttctttag-3'; TाTC-marker forward, 5'-gcaggctacccgattcgtg-3'; ПTाTC-marker re- verse $5^{\prime}$-gggcaacaagagtgaaactcc-3'; ПTTC-marker forward, 5'-ttatcctcttcctcattagcacc-3'; and TTC-marker reverse, 5'-ggggcaagagtgaaactgtcaa-3'; 169B4.GT118 and D21S1225 primers were used as reported (Berry et al, 2000). PCR products were run in a denaturing gel (4.5\% polyacrylamide with $3.3 \%$ crosslinking).

\section{IHC Analysis}

A modification of the avidin-biotin-peroxidase method was applied with 3,3-diaminobenzidine as the chromogen. Sections were incubated overnight at $4^{\circ} \mathrm{C}$ with a monoclonal antibody against TFF1 (Zymed Laboratories, South San Francisco, California). All series included positive controls; negative controls were performed by replacing the primary monoclonal antibody with immunoglobulins of the same class and concentration. A case was considered positive when more than $5 \%$ of cells displayed IHC staining, irrespective of their intensity and localization.

\section{Promoter Methylation Analysis}

Genomic DNA was bisulfite-treated, as previously described (Herman et al, 1996). Amplification of the treated DNAs was performed by cold PCR, as described previously, using the following primers: forward, 5'-attagtggagattattgttttaga-3'; reverse, 5'aaaaaaaacataccttacctatct- $3^{\prime}$. Cycling conditions were 30 seconds at $94^{\circ} \mathrm{C}, 30$ seconds at $55^{\circ} \mathrm{C}$, and 30 seconds at $72^{\circ} \mathrm{C}$ for 35 cycles. PCR products of bisulfite-treated DNA were cloned into the Zero Blunt TOPO PCR cloning kit (InVitrogen, Carlsbad, California) and sequenced using the ABI Prism Dye Terminator Cycle Sequencing kit (Perkin-Elmer) and an $A B I$ Prism 377 DNA Sequencer (Perkin-Elmer). Sequencing was performed with the M13 primers.

\section{Demethylation Treatment}

The human gastric carcinoma-derived cell line GP202 was grown in RPMI (InVitrogen) supplemented with $10 \%$ FBS (InVitrogen), 1\% nystatin (InVitrogen), and $1 \%$ penicillin/streptomycin (InVitrogen) in a $5 \% \mathrm{CO}_{2}$ humidified atmosphere. Cells were seeded at a density of $2 \times 10^{4}$ cells/20-mm dish and allowed to attach over a 24-hour period. Cells were subsequently either incubated with a null control (DMSO as solvent) or with 5-aza-CdR (Sigma-Aldrich, St. Louis, Missouri), to a final concentration of $0.01,0.1,1,5$, or $10 \mu \mathrm{m}$; cells were then allowed to grow for 7 days. At the end of the treatment period, the medium was removed and total RNA was extracted using the method described above for mutation screening. Amplification of the cDNA was performed according to the procedures described above for cold-PCR. Primers for TFF1 and for the housekeeping gene encoding GAPDH were chosen from different exons to exclude amplification of genomic DNA. TFF1 cDNA was amplified by the following primers: forward, 5'-tttggagcagagaggaggcaatg-3'; reverse, 5'-accacaattctgtctttcacgggg- $3^{\prime}$. To standardize mRNA level, GAPDH was amplified by the 
following primers: forward, $5^{\prime}$-accatcttccaggagcgagatc-3'; reverse, 5'-ggatgaccttgcccacag-3'.

\section{Quantitative Real-Time PCR}

PCR using the primers described above for TFF1 CDNA and GAPDH was performed with SYBR Green on an iCycler iQ Real Time Quantitative System (BioRad, Hercules, California). Cycling conditions were 15 seconds at $95^{\circ} \mathrm{C}, 15$ seconds at $57^{\circ} \mathrm{C}$, and 10 seconds at $72^{\circ} \mathrm{C}$ for 35 cycles. The specificity of each PCR reaction was tested by melting curve analysis. $\Lambda c_{t}$ (threshold cycle) values were determined by subtraction of the $c_{t}$ levels between TFF1 and GAPDH after incubation with 5-aza-CdR at different concentrations or with a null control.

\section{Statistical Analysis}

Comparison of genotype frequencies between cases and controls was assessed by the $\chi^{2}$ test. Independent triplicate stimulation experiments were performed for the quantitative real-time PCR analysis and assessed by Student's $t$ test.

\section{References}

Al azzeh ED, Fegert P, Blin N, and Gott P (2000). Transcription factor GATA- 6 activates expression of gastroprotective trefoil genes TFF1 and TFF2. Biochim Biophys Acta 1490: 324-332.

Beck S, Sommer P, dos Santos Silva E, Blin N, and Gott P (1999). Hepatocyte nuclear factor 3 (winged helix domain) activates trefoil factor gene TFF1 through a binding motif adjacent to the TATAA box. DNA Cell Biol 18:157-164.

Berry A, Scott HS, Kudoh J, Talior I, Korostishevsky M, Wattenhofer M, Guipponi M, Barras C, Rossier C, Shibuya K, Wang J, Kawasaki K, Asakawa S, Minoshima S, Shimizu N, Antonarakis S, and Bonne-Tamir B (2000). Refined localization of autosomal recessive nonsyndromic deafness DFNB10 locus using 34 novel microsatellite markers, genomic structure, and exclusion of six known genes in the region. Genomics 68:22-29.

Carvalho B, van der Veen A, Gartner F, Carneiro F, Seruca R, Buys $\mathrm{CH}$, and Kok K (2001). Allelic gains and losses in distinct regions of chromosome 6 in gastric carcinoma. Cancer Genet Cytogenet 131:54-59.

Chomczynski P and Sacchi N (1987). Single-step method of RNA isolation by acid guanidinium thiocyanate-phenolchloroform extraction. Anal Biochem 162:156-159.

Fujimoto J, Yasui W, Tahara H, Tahara E, Kudo Y, and Yokozaki H (2000). DNA hypermethylation at the pS2 promoter region is associated with early stage of stomach carcinogenesis. Cancer Lett 149:125-134.

Gärtner F, David L, Seruca R, Machado JC, and SobrinhoSimões M (1996). Establishment and characterization of two cell lines derived from human diffuse gastric carcinomas xenografted in nude mice. Virchows Arch 428:91-98.

Herman JG, Graff JR, Myohanen S, Nelkin BD, and Baylin SB (1996). Methylation-specific PCR: A novel PCR assay for methylation status of $\mathrm{CpG}$ islands. Proc Natl Acad Sci USA 93:9821-9826.
Lefebvre O, Chenard MP, Masson R, Linares J, Dierich A, LeMeur M, Wendling C, Tomasetto C, Chambon P, and Rio MC (1996). Gastric mucosa abnormalities and tumorigenesis in mice lacking the pS2 trefoil protein. Science 274:259-262.

Machado JC, Carneiro F, Blin N, and Sobrinho-Simões M (1996a). Pattern of pS2 protein expression in premalignant and malignant lesions of gastric mucosa. Eur $\mathrm{J}$ Cancer Prev 5:169-179.

Machado JC, Carneiro F, Ribeiro P, Blin N, and SobrinhoSimões M (1996b). pS2 protein expression in gastric carcinoma. An immunohistochemical and immunoradiometric study. Eur J Cancer 32A:1585-1590.

Martin V, Ribieras S, Song-Wang X, Rio MC, and Dante R (1995). Genomic sequencing indicates a correlation between DNA hypomethylation in the $5^{\prime}$ region of the pS2 gene and its expression in human breast cancer cell lines. Gene 157:261-264.

Martin V, Ribieras S, Song-Wang XG, Lasne Y, Frappart L, Rio MC, and Dante R (1997). Involvement of DNA methylation in the control of the expression of an estrogen-induced breast-cancer-associated protein (pS2) in human breast cancers. J Cell Biochem 65:95-106.

Motoyama T, Hojo H, and Watanabe H (1986). Comparison of seven cell lines derived from human gastric carcinomas. Acta Pathol Jpn 36:65-83.

Park WS, Oh RR, Park JY, Lee JH, Shin MS, Kim HS, Lee HK, Kim YS, Kim SY, Lee SH, Yoo NJ, and Lee JY (2000). Somatic mutations of the trefoil factor family 1 gene in gastric cancer. Gastroenterology 119:691-698.

Rio MC, Bellocq JP, Daniel JY, Tomasetto C, Lathe R, Chenard MP, Batzenschlager A, and Chambon P (1988). Breast cancer-associated pS2 protein: Synthesis and secretion by normal stomach mucosa. Science 241:705-708.

Sakata K, Tamura G, Nishizuka S, Maesawa C, Suzuki Y, Iwaya T, Terashima M, Saito K, and Satodate R (1997). Commonly deleted regions on the long arm of chromosome 21 in differentiated adenocarcinoma of the stomach. Genes Chromosom Cancer 18:318-321.

Sekiguchi M, Sakakibara K, and Fujii G (1978). Establishment of cultured cell lines derived from a human gastric carcinoma. Jpn J Exp Med 48:61-68.

Sommer P, Blin N, and Gott P (1999). Tracing the evolutionary origin of the TFF-domain, an ancient motif at mucous surfaces. Gene 236:133-136.

Thim L (1989). A new family of growth factor-like peptides. 'Trefoil' disulphide loop structures as a common feature in breast cancer associated peptide (pS2), pancreatic spasmolytic polypeptide (PSP), and frog skin peptides (spasmolysins). FEBS Lett 250:85-90.

Vollmers HP, Stulle K, Dämmrich J, Pfaff M, Papadopoulos Th, Betz C, Saal K, and Müller-Hermelink HK (1993). Characterization of four new gastric cancer cell lines. Virchows Arch B Cell Pathol 63:335-343.

Wong WM, Poulsom R, and Wright NA (1999). Trefoil peptides. Gut 44:890-895.

Wright NA, Poulsom R, Stamp G, Van Norden S, Sarraf C, Elia G, Ahnen D, Jeffery R, Longcroft J, Pike C, Rio MC, and Chambon P (1993). Trefoil peptide gene expression in gastrointestinal epithelial cells in inflammatory bowel disease. Gastroenterology 104:12-20. 